\title{
Walkability Design for Urban Public Housing Park
}

\author{
Dasimah bt Omar ${ }^{1 *}$, Kamarul Ariff Omar², Saberi Othman ${ }^{3}$, Zaharah Mohd Yusoff ${ }^{4}$ \\ 1 Faculty of Architecture, Planning and Surveying, Universiti Teknologi Mara (UiTM), 40450 Shah Alam, Selangor, Malaysia \\ ${ }^{2}$ Faculty of Architecture, Planning and Surveying, Universiti Teknologi Mara (UiTM), 40450 Shah Alam, Selangor, Malaysia \\ ${ }^{3}$ Faculty of Science and Mathematics, Universiti Pendidikan Sultan Idris(UPSI), 35900 Tanjong Malim, Perak Malaysia \\ ${ }^{24}$ Faculty of Architecture, Planning and Surveying, Universiti Teknologi Mara (UiTM), 40450 Shah Alam, Selangor, Malaysia
}

\begin{abstract}
The walkability approach is essential to ensure the connectivity among space in the urban area. The design should be appropriate, safety, maximize and capable of reaching every inch of the spaces, just by walking. Good connectivity must allow people to walk freely and accessible in many ways. People have great chances to meet each other or having potential outdoor activities without any challenges. This study aims to measure the user perception of the existing spaces in the urban public housing environment that been covered and uncovered with the walkability linkages. The objectives of this study are to identify the existing pedestrian linkages in the study area; to investigate the user perception of the existing walkability system in the study area, and finally to conclude and provide a better solution for better walkability opportunity among residents to access the public park.

(C) 2016. The Authors. Published for AMER ABRA by e-International Publishing House, Ltd., UK. This is an open access article under the CC BY-NC-ND license (http://creativecommons.org/licenses/by-nc-nd/4.0/).

Peer-review under responsibility of AMER (Association of Malaysian Environment-Behaviour Researchers), ABRA (Association of Behavioural Researchers on Asians) and cE-Bs (Centre for Environment-Behaviour Studies), Faculty of Architecture, Planning \& Surveying, Universiti Teknologi MARA, Malaysia.
\end{abstract}

Keywords:outdoor space; pedestrian linkages; public parks; walkability behavior

\section{Introduction}

Urban is a rapidly growing area. It is a place for people to get various facilities and services. Public housing is one of the facilities growth in the urban space and creating several unit of neighbourhood community. Therefore, the urban space often experiences problems of pollution, traffic congestion, connectivity among spaces, and crimes. The increasing of the population due to the rapid growth of housing sector will continue to add more crowded in the urban space. It also decreases the safety of the people who tend to walk in the urban spaces. Therefore, planning and control needed to reduce such problems.

${ }^{*}$ Corresponding author. Tel.:

E-mail address: dasimah629@salam.uitm.edu.my

2398-4287 @ 2016. The Authors. Published for AMER ABRA by e-International Publishing House, Ltd., UK. This is an open access article under the CC BY-NC-ND license (http://creativecommons.org/licenses/by-nc-nd/4.0/).

Peer-review under responsibility of AMER (Association of Malaysian Environment-Behaviour Researchers), ABRA (Association of Behavioural Researchers on Asians) and CE-Bs (Centre for Environment-Behaviour Studies), Faculty of Architecture, Planning \& Surveying, Universiti Teknologi MARA, Malaysia.

DOI: http://dx.doi.org/10.21834/e-bpj.v1i3.375 
There are some conversations regarding on why people refuse to walk more in the urban space. The argument mainly refers to the distance between two points that cause people refused to walk. People who live in the urban public housing hope that there are facilities provided for them to spend their leisure and weekend freely and accessible at any time. These studies had given the idea to conduct a study on the pedestrian linkages in the urban public housing park. A hypothesis has been suggested as the walkable space may affect user behavior and shaping their daily movement.

In planning a walkway system that works, the selection of a necessary and organized space is outstanding as a start toward the path that connects the spaces in our surrounding environment. The objectives of this study are to identify the existing pedestrian linkages in the study area; to investigate the user perception of the present walkability system in the study area, and finally to conclude and provide a better solution for better walkability opportunity among residents to access the public park. The result of this study could give a basic start to improve the cultural and behavior of urban people in retrieving their surrounding environment especially outdoor space and public park.

\section{Literature Review}

\subsection{Walkability}

Walkability is designed to show an increased rate of people walking by. The early history of human development begins when a human walks. Walking is an important thing in human life because human beings are always running to do something. Traditionally, walking has been overlooked by the transportation research, which focused more on motorized travel. The walking environment was ignored continuously even more, and until recently relatively little research has been done on walking behavior in the relation to the walking environment. (Southworth and BenJoseph, 2003), and thus, early road design manuals paid less attention to the walking environment.

Thus, by walking, it helps to mobilize local activities, especially urban spaces. This movement is one of survival for humans, just like breathing and talking. As a consequence, walkability word here means increasing the rate of progress in some areas by humans. (Eunyoung and Sardari Sayyar, 2012). Walkability is not just to increase the number of walking but also to push people to walk more rather than use the vehicle. This could slow the pollution, especially in the urban area to increase and to spread around the environment. This also can create the interrelation between spaces as it can be more interacted for both sides.

Walkability is not only about increasing the amount of walking but to encourage a pace of travel, via walking, that allows for positive interactions between inhabitants to take place. People will only be encouraged to walk when the pedestrian environments reinforce their various pursuits. Therefore, studies on walkability have focused on how well the built environment is designed to suit a city walker's priorities. Indeed, a livable city is designed, through the built environment, to facilitate the well-being of its people.

The provision of walkways generally covered the spaces, building structures and a small amount of development that appear in that area. For an example; residential areas, the walkways are seen to be existing nearby the recreational area, the main road, and the space between buildings. Walkability design should emphasise particular element such as building orientation; block length; building height, and building scale (Richa Singh, 2016). Therefore, it is better to identify the surrounding built environment features to enhance the walkability level among the user.

Walkability in the urban neighbourhood, space is influenced by the accessibility perception of the user. Thus, the user needs to understand the route of the pedestrian as they can mobilize ease and comfortable (Diyanah Inani Azmi et al., 2013). In deriving the neighbourhood walkability, the planner should estimate and experience the walking behavior at the other place, the experience will help to improvise and increase the sense of walking upon the new design of the pedestrian network.

Walking experience is a physical activity and need to be developed along with specific variables such as safety, security, convenience and attractiveness (Hafazah Abdul Karim and Diyanah Inani Azmi, 2013). The behavioral of walking experience among people is affected by the availability of walkable element (pedestrian, sidewalk) and the awareness of the people upon the visibility of these items (Shuhana Shamsuddin, 2012). 


\subsection{Pedestrian Linkages}

The importance of pedestrian design in urban spaces, traffic infrastructures and during evacuations and emergencies is growing, unleashed by the ever increasing capacity demands and complexities of the built environment. Airports, sports centers, large public and commercial buildings, big events as well as shopping centers or crossings in traffic management are typical examples of the need for safe pedestrian design.

Destination accessibility measures the ease with reach the trip generation. Of course, there are many reasons for travel, which means that having access to a diversity of businesses within proximity is likely to encourage residents to walk. The meta-study found that destination accessibility is the most important factor in reducing the rate of driving, more so than neighborhoods density, mixed land use, or street design combined.

In developing pedestrian network, comfortable and safety are required to enrich the purpose of this facility (Lily Mauliani et al., 2015). The sidewalk is one of the key components for a walkable neighbourhood. A proper path will encourage people to walk mainly and interact with the surrounding environment feature and peoples (Raja Noriza Raja Ariffin and Rustam Khairi Zahari, 2013). There is a relationship between physical environment parameters and active living lifestyle, with a small change in physical environment feature (pedestrian), it can improve the communities walking behaviour (Ebru Chubuku, 2013).

Improving accessibility of pedestrian in the neighbourhood should come with the decision-making process participated by the professional bodies and governments, and the local peoples (Valentin Grecu and Tudor Morar, 2013).

\section{Research Methodology}

\subsection{Study Area}

Projek Perumahan Rakyat (PPR) Kerinchi is the public low-cost housing project has been selected as the study area. The site is strategically located at the centre of Lembah Pantai district in The Federal Territory of Kuala Lumpur. This housing scheme consists of a various group of people from different ages and races. PPR Kerinchi was the squatters' resettlement programme of villagers from Kampung Pantai Dalam area which is now known as Bangsar South commercial area.

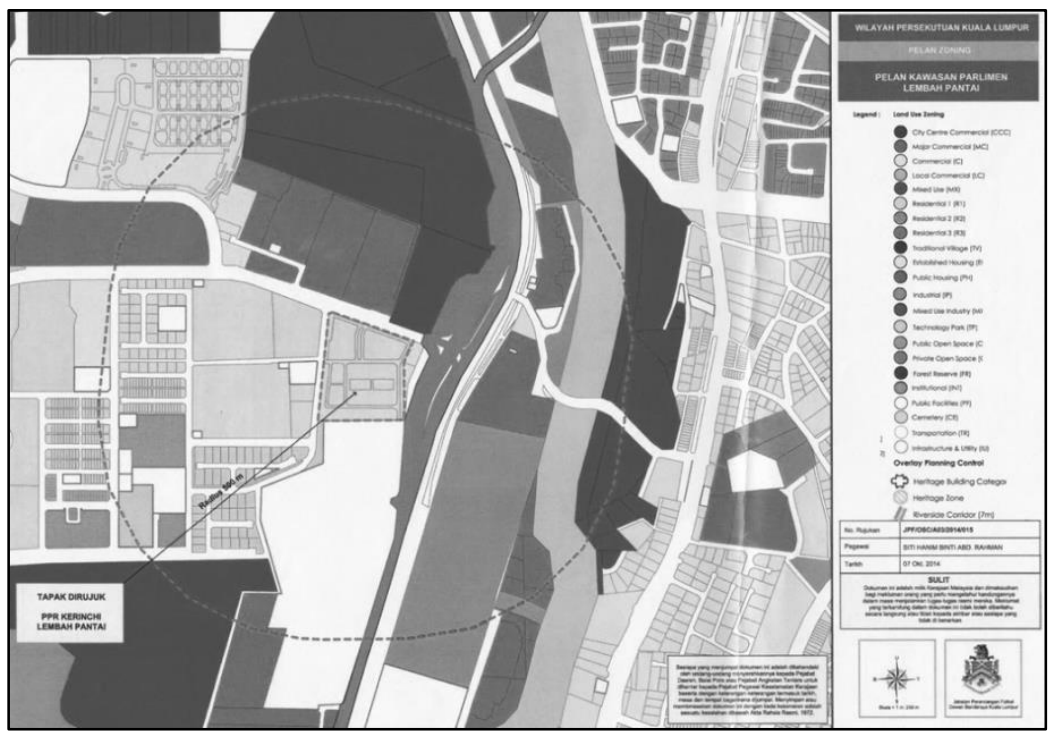

Figure 1: Study Area 


\subsection{Data Collection}

This study mainly run by a set of the questionnaire through the selected variables and highlighted issues from the last FGD sessions. The questionnaire contains 2 (two) parts which is Part A (Respondents' background) and Part B on their satisfaction level on the pedestrian linkages in the public housing residential community. A total of 400 questionnaires were distributed to the youth age 15-25 randomly. These respondents were picked-up using 'snowball' sampling technique due to difficulty to define accurately the exact number of youth live there. This survey took about 2 (two) weeks because most of the respondents were available during their leisure time at about five p.m. after school and working hours.

\section{Findings}

\subsection{Observation on the Existing Pedestrian Linkages.}

The study started by conducting an observation to the area to identify the existing pedestrian networking system. This step has led to some issue and problem regarding the pedestrian accessibility, availability, comfortability, connectivity, and maintenance. There are two types of pedestrian linkages exist in the study area which is sidewalk and jogging track. According to Figure 1, this is one of the sidewalks that connected the whole area and between the buildings. The pedestrian seems to be in a good condition, but people decline to use it because it does not connect the whole area.

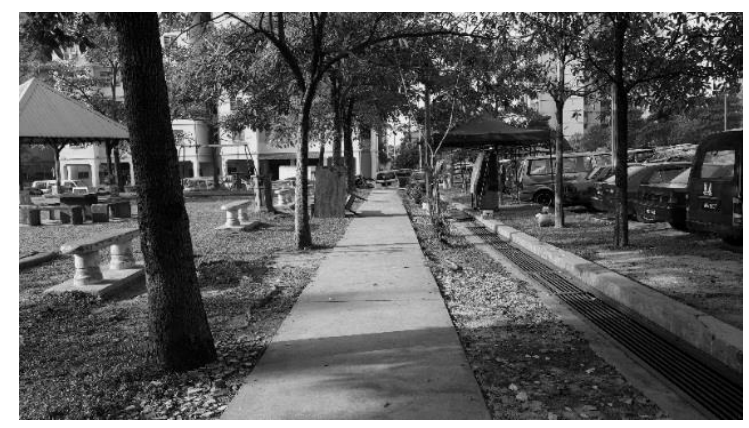

Figure 2: Existing Sidewalk

Another walkable space in this study area is the jogging track. This pathways is most likely a facilities for the local to perform outdoor activities during leisure time. Figure 3 shows that the jogging track is less usable by the locals because the area is too small and almost crowded by the children at every evening, especially on the weekend. As the jogging track is not compulsory, categorized as pedestrian linkages, but it remains built as walkable space in the public housing area.

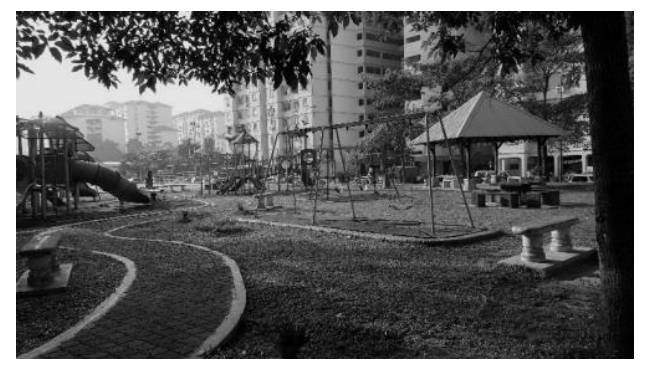

Figure 3: Jogging Track 


\subsection{Users' Perception on the Existing Pedestrian Linkages.}

Many previous studies have shown that built environment often influences the people walking behavior. There are other studies indicate that an encouraging walkable design atmosphere would attract lively walking behavior. Therefore, one of the survey questions was to examine the level of users' satisfaction upon the pedestrian linkages and how the pedestrian influence was walking activity among the respondents.

Based on the Table 1, it shows the value on the level of respondents' satisfaction upon the pedestrian linkages. Most of the numbers indicated the value of three (3) to four (4) for each variables, which shows the respondents felt moderate with this facilities. This result has demonstrated that, the development of pedestrian space did not reach the highest value of satisfaction among the users (youth). As the 'availability' value of jogging track is 3.30 , this shows that youth felt not very satisfied with this space. This resulted in the factor where youth were in actively involved in outdoor activities because the connection spaces are limited. The level of comfortable also recorded the mean around 3.5 to 3.75 only; this is because the respondents did not achieve the comfortability level especially for the jogging track.

Table 1 Level of Respondents' Satisfaction on Pedestrian Linkages

\begin{tabular}{|c|c|c|c|c|c|c|}
\hline \multirow{3}{*}{ Outdoor space } & & \multicolumn{5}{|l|}{ Variables } \\
\hline & & ${ }^{*}$ Availability & ${ }^{*}$ Comfortability & ${ }^{*}$ Range & ${ }^{*}$ Accessibility & *Maintenance \\
\hline & $\mathrm{N}$ & 400 & 400 & 400 & 400 & 400 \\
\hline \multirow{2}{*}{ Pedestrian linkages } & Mean & 3.78 & 3.75 & 3.91 & 3.96 & 3.76 \\
\hline & Std. Deviation & 1.031 & 1.004 & 1.008 & 1.000 & .975 \\
\hline \multirow{2}{*}{ Jogging Track } & Mean & 3.30 & 3.51 & 3.59 & 3.59 & 3.52 \\
\hline & Std. Deviation & 1.214 & 1.149 & 1.119 & 1.071 & 1.124 \\
\hline
\end{tabular}

Referring to the pedestrian linkages column, the values do not reach the satisfy level of four (4) because the respondents felt that the facility is not qualified to assist their daily mobility and also enhance their trip generation. This problem is due to the barriers created by some of the locals who park their vehicles covering the sidewalk and blocking this pathway. Even though, the accessibility value is high (3.96), the vehicles had stamped the pedestrian existence among the outsiders who came to this neighbourhood almost twice a week for the 'night market' on Wednesday and Saturday. This problem seems to be harsh during the night as the people live nearby the community area come to the food court.

During the weekend, the respondents felt less comfortable to walk in their public park because the vehicles' number double up and concealed the whole pedestrian space, especially by motorcycles. This issue has decreased the respondents' attitude to be actively involved in outdoor activities and walk freely. This has also affected jogging track which has been covered by the illegal car parking. This has resulted that the connectivity between linkages is low and decrease the range of walking distance in walkable design space. Besides, the respondents often walk at the inappropriate space rather than the pedestrian linkages offered.

Finally, the maintenance variable indicated the second lowest mean which is 3.76. During the observation, and it was found that some of the pathways have been damaged and dented by scrub. This has verified the low maintenance occurred and happened for an extended period. Moreover, the pedestrian design in the study area is not well planned because it only appears as sidewalk, and does not connecting buildings with the surrounding area. Therefore, the current pedestrian design is not relevant and well practice by the users as they could not access to the surrounding area freely by walking.

\section{Walkable Space at the Urban Public Housing Park}

\subsection{Increase the Connectivity of Pedestrian Linkages}

Connectivity describes and controls the movement of city's urban form, its amount of the interconnected, and 
relieve with which pedestrians can access destinations via the pedestrian network. As the number of connections increases, block lengths become shorter and more links are created providing increased route choices to make a particular trip. Increasing connectivity decreases the walking distance and walking time by offering more direct access to destinations via the street (or pedestrian) network. As connectivity decreases, the attractiveness of walking also decreases because walking distances and time to reach destinations increases due to out-of-direction travel and backtracking. Connectivity has a considerable impact on walkability and is dependent on the layout of the street network and the extent that sidewalks and pedestrian links are provided. If connectivity is not considered during the planning of a neighbourhood, it is far harder to create connectivity after the community is constructed.

\subsection{Planning For Variety Pedestrian Route Choice.}

Planning for physical development for safety and security on pedestrian is important to create a variety choice of route. Every pedestrian path must be developed with more than one intersections. Therefore, pedestrians can have variety of walking route as it could also be escape routes when anything bad happens to them. The proper design of curb cuts and entrance ramps is essential to the safety of people who are visually impaired and people using wheelchairs and other mobility aids, such as canes and walkers. Curb cuts in sidewalks accommodate baby strollers, delivery carts and anything else on wheels that need to be pushed or pulled. It is recommended that the slope of a curb cut or entrance ramp be gradual with a non-slip surface. Most ramps should also have railings to improve safety.

\section{Conclusion}

As overall conclusion, providing walkable design in residential areas should consider various aspects and a proper guideline is required to serve the community equally. This paper has revealed some of the correlation among pedestrian linkage and the neighbourhood in the urban public housing, as to create a better living space for the youth. Pedestrian linkages are necessary to develop more walkability behaviour and enhanced the lively community along with outdoor activities especially for youth. The ability to meet the need of good walkable design should be the main focus of the community residential areas. Governments' agencies need to indicate more policies in designing the built environment, and most important to create livable community and interactive people in the urban public housing park.

Finally, most important in all pedestrian linkages design is how people tend to walk and continue to be connected among them. Within this appropriate recommendation, the walkable design in the urban public housing park should be much better and effective to be used by the people.

\section{Acknowledgement}

This study is made possible by the Long-term Research Grant Scheme (LRGS 2014-0006-106-42), Universiti Pendidikan Sultan Idris Perak associated with Universiti Teknologi MARA Shah Alam, and Universiti Putra Malaysia.

\section{References}

Ariffin, R. N. R., \& Zahari, R. K. (2013). Perceptions of the Urban Walking Environments. Procedia - Social and Behavioral Sciences, 105, 589597. doi:10.1016/j.sbspro.2013.11.062

Azmi, D. I., Karim, H. A., \& Ahmad, P. (2013). Comparative Study of Neighbourhood Walkability to Community Facilities between Two Precincts in Putrajaya. Procedia - Social and Behavioral Sciences, 105, 513-524. doi:10.1016/j.sbspro.2013.11.055

Cubukcu, E. (2013). Walking for Sustainable Living. Procedia - Social and Behavioral Sciences, 85, 33-42. doi:10.1016/j.sbspro.2013.08.335 
Grecu, V., \& Morar, T. (2013). A Decision Support System for Improving Pedestrian Accessibility in Neighborhoods. Procedia - Social and Behavioral Sciences, 92(Lumen), 588-593. doi:10.1016/j.sbspro.2013.08.722

Karim, H. A., \& Azmi, D. I. (2013). Convenience and Safety of Walking Experience in Putrajaya Neighbourhood Area. Procedia - Social and Behavioral Sciences, 101, 318-327. doi:10.1016/j.sbspro.2013.07.206

Mauliani, L., Purwantiasning, A. W., \& Aqli, W. (2015). Designing Better Environment by Providing Pedestrian Way for Pedestrian. Procedia Social and Behavioral Sciences, 179, 80-93. doi:10.1016/j.sbspro.2015.02.412

Shamsuddin, S., Hassan, N. R. A., \& Bilyamin, S. F. I. (2012). Walkable Environment in Increasing the Liveability of a City. Procedia - Social and Behavioral Sciences, 50(July), 167-178. doi:10.1016/j.sbspro.2012.08.025

Singh, R. (2016). Factors Affecting Walkability of Neighborhoods. Procedia - Social and Behavioral Sciences, 216(October 2015), 643-654. doi:10.1016/j.sbspro.2015.12.048 